\title{
Neonatal hypoglycaemia in Nepal 1. Prevalence and risk factors
}

Deb K Pal, Dharma S Manandhar, Sujan Rajbhandari, John M Land, Navin Patel, Anthony M de L Costello

\begin{abstract}
Aims-To measure the prevalence of hypoglycaemia among newborn infants in Nepal, where classic risk factors prevail, and to evaluate their importance.

Methods-A cross sectional study was done of 578 term newborn infants aged 0 to 48 hours on the postnatal wards of a government maternity hospital in Kathmandu, with unmatched case-control analysis of risk factors for moderate hypoglycaemia (less than $2.0 \mathrm{mmol} / \mathrm{l}$ ). Results-Two hundred and thirty eight $(41 \%)$ newborn infants had mild (less than $2.6 \mathrm{mmol} / \mathrm{l})$ and $66(11 \%)$ moderate hypoglycaemia. Significant independent risk factors for moderate hypoglycaemia included postmaturity (OR 2.62), birthweight under $2.5 \mathrm{~kg}$ (OR 2.11), small head size (OR 0.59), infant haemoglobin $>210$ g/1 (OR 2.77), and raised maternal thyroid stimulating hormone (TSH) (OR 3.08). Feeding delay increased the risk of hypoglycaemia at age 12-24 hours (OR 4.09). Disproportionality affected the risk of moderate hypoglycaemia: lower with increasing ponderal index (OR 0.29), higher as the head circumference to birthweight ratio increased (OR 1.41). Regression expressing blood glucose concentration as a continuous variable revealed associations with infant haemoglobin (negative) and maternal haemoglobin (positive), but no other textbook risk factors.
\end{abstract}

Conclusions-Neonatal hypoglycaemia is more common in a developing country, but may not be a clinical problem unless all fuel availability is reduced. Some textbook risk factors, such as hypothermia, disappear after controlling for confounding variables. Early feeding could reduce moderate hypoglycaemia in the second 12 hours of life. The clinical significance of raised maternal TSH and maternal anaemia as prenatal risk factors requires further research.

(Arch Dis Child Fetal Neonatal Ed 2000;82:F46-F51)

Keywords: hypoglycaemia; Nepal; hypothermia; thyroid stimulating hormone

Neonatal hypoglycaemia is an avoidable cause of mortality and neurodevelopmental impairment. Neonatal mortality accounts for $50-60 \%$ of all infant deaths in developing countries. ${ }^{1}$ Hypoglycaemia, combined with other fuel deficiencies which may occur in association with fetal malnutrition, polycythaemia, birth asphyxia, hypothermia or apnoea, may have an important role in some of these early deaths. Neurodevelopmental impairment is 3.5-fold higher in preterm infants with recurrent mild hypoglycaemia, ${ }^{2}$ and there is some evidence that glucose concentrations below $2.6 \mathrm{mmol} / \mathrm{l}$ lead to acute neurophysiological changes in newborn infants. ${ }^{3}$ In developing countries, where classic risk factors such as low birthweight, hypothermia, and delays in the onset of breastfeeding are common, hypoglycaemia could be a widespread problem among newborn infants.

However, the prevalence and associations of hypoglycaemia in these settings have not been accurately described. The prevalence of hypoglycaemia in different populations is difficult to compare because of differing definitions, populations, labour room practices, infant ages and technical methods. Previous studies of risk factors for hypoglycaemia have described small numbers of infants, did not quantify relative risk, nor control for important confounding variables such as postnatal age. ${ }^{56}$

A pilot study in Nepal applying glucose test strips to heelprick samples showed that $38 \%$ of neonates had a blood glucose concentration below $2.6 \mathrm{mmol} / 1$ during the first three days of postnatal life, compared with $18 \%$ of neonates in Newcastle, England, studied during the same postnatal period. ${ }^{78}$ This study aimed to measure precisely, using a standard laboratory glucose method, the severity and prevalence of hypoglycaemia among apparently healthy neonates, and to evaluate the relative importance of maternal and infant (prenatal and postnatal) risk factors, to design appropriate strategies for prevention.

\section{Methods}

Nepal is a low income south Asian country with poor health indicators and an infant mortality estimated at 95 per 1000 live births. ${ }^{9}$ The study was conducted in Prasuti Griha, the largest maternity unit in the country hosting 15000 births annually, between June 1993 and March 1994. The hospital promotes early breastfeeding and the prevention of neonatal hypothermia, but the latter remains a problem. ${ }^{10}$ The average duration of stay is $2-3$ days.

The study was approved by the hospital authorities and the Nepal Health Research Council. A full verbal explanation of the study was given to mothers and their permission sought for enrolment.

The prevalence of hypoglycaemia was investigated in a cross sectional study of routine uncomplicated deliveries. Because clinical 
interventions would affect measurements of blood glucose and other metabolites, admissions to the special care baby unit-about $10 \%$ of all deliveries - were excluded. Five hundred and seventy eight mother-infant pairs were studied, 278 in the warm season, and 300 during the cold season. To investigate risk factors, an unmatched case-control design was used to compare infants with moderate hypoglycaemia (glucose less than $2.0 \mathrm{mmol} / \mathrm{l}$ ) with all other infants, using logistic regression. Stepwise linear regression was used to study the determinants of blood glucose expressed as a continuous variable.

Enrolment of mother-infant pairs took place at one of three phlebotomy sessions, during the morning, afternoon, or evening. Infants under 48 hours of age were categorised into eight hour age groups. The first child in each age group entered in the labour ward register was enrolled into the study. In case of refusal, the second or third name was used. If available, one infant in each age group was enrolled every day.

Maternal clinical details (household size, pregnancy, and labour) were recorded, along with immediate postnatal height and weight. Maternal height was measured to the nearest $0.5 \mathrm{~cm}$, using a portable stadiometer (Child Growth Foundation); maternal weight using Soenhle adult scales; infant length to the nearest $0.5 \mathrm{~cm}$ using a Rollametre (Child Growth Foundation); infant weight to the nearest $50 \mathrm{~g}$ using Soenhle electronic infant weighing scales; head circumference using a newborn tape measure; Apgar scores were noted; and gestational age was assessed using the Capurro method. ${ }^{11}$ Infant rectal temperature was recorded two minutes after inserting the thermometer. The time of phlebotomy and the most recent feed were recorded together with the ambient temperature. If hypoglycaemia (cotside glucose test strips) or hypothermia was detected, appropriate interventions such as feeding or warming the infant were started.

Venous blood samples were collected from mothers and infants and divided: $400 \mu \mathrm{lmixed}$ with an equal amount of freshly prepared $6 \%$ perchloracetic acid (PCA); $400 \mu \mathrm{l}$ diluted with heparin; 200-400 $\mu 1$ stored as serum. Samples were put on ice and centrifuged at $3000 \mathrm{rpm}$ for five minutes within 90 minutes of collection. Supernatant fluids were stored at $-20^{\circ} \mathrm{C}$ awaiting transfer in liquid nitrogen for further analysis. Bedside maternal and infant haemoglobin measurements were taken using a Hemocue microcuvette method.

Glucose was measured using the Roche Ultimate glucose oxidase method for glucose on the COBAS Fara analyser. In the presence of peroxidase, plasma free thyroxine (T4) and thyroid stimulating hormone (TSH) were measured using Vidas enzyme linked fluorescent assays according to the manufacturer's (BioMérieux) protocol.

The accuracy, precision, limits of detection and coefficient of variation for glucose assay were $98 \%, 2 \%, 0.2 \mathrm{mmol} / 1$ and $1.0 \%$; for $\mathrm{T} 4$ they were $95 \%, 5 \%, 0.2 \mathrm{pmol} / 1$ and $5.4 \%$; and for $\mathrm{TSH}$ these were $98 \%, 5 \%, 0.1 \mathrm{mIU} / \mathrm{ml}$ and $3.6 \%$.

After double entry into a computer database, data were analysed using STATA 5.0 for Macintosh. Missing values and range errors were corrected by reference to the original database. A reduced complete dataset was also generated by eliminating all subjects with missing values. Analyses of odds ratios were repeated with the reduced dataset but showed no significant differences, so the full dataset is reported.

Associations between outcome groups with known risk factors and other important hypothesised exposures were tested univariately by calculating odds ratios with $95 \%$ confidence intervals. Significant risk factors after univariate analysis were entered into a logistic regression model to calculate the effects of individual risk factors adjusted for confounding effects of other exposures. Regression coefficients are given with $95 \%$ confidence intervals and exact $p$ values. Multivariate population attributable risk fractions were calculated using the method described by Bruzzi et al. ${ }^{12}$

To evaluate independent associations with population blood glucose, important independent variables were entered into a forward stepwise linear regression analysis and only those with $\mathrm{p}$ values of less than 0.1 were included in the final model.

\section{Results}

The clinical and anthropometric characteristics of the mothers and infants are summarised in table 1. Overall, this population of mothers was young, many did not attend antenatal clinics, and most were primigravidae. Maternal nutritional status was poor: most mothers were stunted and anaemic. Over $80 \%$ of mothers were from poor households and used the "free" postnatal wards which levied only a small daily charge (about US\$0.5). Only 4\% of women with an assisted delivery were included because infants transferred for special care were not eligible for the study.

The mean birthweight $(2690 \mathrm{~g})$, was low compared with that of industrialised country norms, and the low birthweight prevalence high at $32 \%$, which is close to the reported national average for India (no data available for Nepal). A quarter of infants had not been fed in the previous three hours, although this partly reflected their young age: $58 \%$ of neonates under 12 hours of age had not been fed. All newborn infants studied in winter $(n=300)$ were nursed in temperatures below the World Health Organisation recommended minimum of $25^{\circ} \mathrm{C}$, whereas in summer all $(\mathrm{n}=278)$ were nursed in temperatures above $25^{\circ} \mathrm{C}$.

Of 578 infants studied, $238(41 \%, 95 \%$ CI 37.2 to 45.2$)$ had mild, and $66(11 \%, 8.8$ to 14.0) moderate, hypoglycaemia (table 2). There was a steady increase in mean blood glucose with age, from 2.67 (SD 0.88 ) $\mathrm{mmol} / 1$ in the first 12 hours to 3.24 (SD 0.84 ) $\mathrm{mmol} / 1$ in infants 36 to 48 hours of age.

In univariate analysis hypoglycaemic neonates were significantly more likely to be younger (OR $0.98,95 \%$ CI 0.96 to 1.00 ), to 
Table 1 Clinical characteristics of the study mothers and newborn infants

\begin{tabular}{|c|c|c|c|}
\hline Variable & $\begin{array}{l}\text { Number (\%) } \\
\text { or mean [SD] }\end{array}$ & Range & $n=$ \\
\hline \multicolumn{4}{|l|}{ Maternal } \\
\hline Age (years) & $22.1[3.9]$ & $15-40$ & 577 \\
\hline Height $(\mathrm{cm})$ & $152.6[6.1]$ & $136-172$ & 563 \\
\hline Weight (kg) & $49.4[6.0]$ & $36-81$ & 564 \\
\hline Body mass index & $21.2[2.2]$ & $15-31$ & 563 \\
\hline Haemoglobin $(\mathrm{g} / \mathrm{dl})$ & $11.0[2.1]$ & $4-18.6$ & 574 \\
\hline Free T4 & $14.1[3.6]$ & $5.5-34.3$ & 559 \\
\hline TSH & $3.05[2.43]$ & $0.2-26.2$ & 559 \\
\hline$<5 \mathrm{IU} / 1$ & $477(85 \%)$ & & \\
\hline$>5 \mathrm{IU} / 1$ & $82(15)$ & & \\
\hline \multicolumn{4}{|l|}{ Pregnancy } \\
\hline Parity & & & 576 \\
\hline Primiparate & $369(64)$ & & \\
\hline Multiparate & $207(36)$ & & \\
\hline Antenatal visits & & & 572 \\
\hline None & $303(53)$ & & \\
\hline One/two & $78(14)$ & & \\
\hline More than two & $191(33)$ & & \\
\hline Gestational age & & & 576 \\
\hline Term & $530(92)$ & & \\
\hline Post term & $46(8)$ & & \\
\hline \multicolumn{4}{|l|}{ Infant mean (SD) } \\
\hline Age at sampling (hrs) & $21.3(12.7)$ & $0-55$ & 578 \\
\hline Sex & & & 577 \\
\hline Male & $280(49)$ & & \\
\hline Female & $297(51)$ & & \\
\hline Birthweight & & & 577 \\
\hline$<2.5 \mathrm{~kg}$ & $183(32)$ & & \\
\hline$>2.5 \mathrm{~kg}$ & $394(68)$ & & \\
\hline Birthweight (kg) & $2.69[0.4]$ & $1.7-3.9$ & 577 \\
\hline Birth length $(\mathrm{cm})$ & $47.2[2.1]$ & $41-54$ & 576 \\
\hline Ponderal index & $2.5[0.29]$ & $1.6-4.0$ & \\
\hline Head size $(\mathrm{cm})$ & $32.6[1.3]$ & $29-42$ & 575 \\
\hline Rectal temperature & $36.5[0.76]$ & $33.9-39.2$ & 574 \\
\hline$<36$ & $114(20)$ & & \\
\hline$>36$ & $460(80)$ & & \\
\hline Infant haemoglobin (g/dl) & $17.5(2.5)$ & $9-25$ & 572 \\
\hline$<21 \mathrm{~g} / \mathrm{dl}$ & $533(93)$ & & 572 \\
\hline$>21 \mathrm{~g} / \mathrm{dl}$ & $39(7)$ & & \\
\hline Free T4 & $29.4[9.7]$ & $11-70$ & 558 \\
\hline Infant TSH & $23.9[16.6]$ & $1.4-170$ & 556 \\
\hline Last feed & & & 577 \\
\hline$<3 \mathrm{hrs}$ & $436(76)$ & & \\
\hline$>3 \mathrm{hrs}$ & $141(24)$ & & \\
\hline Apgar score & & & 576 \\
\hline$<7$ at $5 \mathrm{~min}$ & $133(23)$ & & \\
\hline$>7$ at $5 \mathrm{~min}$ & $443(73)$ & & \\
\hline \multicolumn{4}{|l|}{ Environment } \\
\hline Ambient temperature & & & 578 \\
\hline$<25^{\circ} \mathrm{C}$ & $300(52)$ & & \\
\hline$>25^{\circ} \mathrm{C}$ & $278(48)$ & & \\
\hline
\end{tabular}

Table 2 Prevalence (\%) of hypoglycaemia in 578 neonates less than 48 hours of age born after an uncomplicated delivery

\begin{tabular}{lcc}
\hline $\begin{array}{l}\text { Definition of case } \\
\text { by blood glucose in hours }\end{array}$ & $<2.6$ mmol/l & $<2.0$ mmol/l \\
\hline $0-6(\mathrm{n}=73)$ & $35(48)$ & $12(16)$ \\
$6-12(\mathrm{n}=97)$ & $53(55)$ & $13(13)$ \\
$12-18(\mathrm{n}=72)$ & $25(35)$ & $8(11)$ \\
$18-24(\mathrm{n}=106)$ & $50(47)$ & $11(10)$ \\
$24-30(\mathrm{n}=85)$ & $34(40)$ & $13(15)$ \\
$30-36(\mathrm{n}=58)$ & $22(38)$ & $4(7)$ \\
$36-42(\mathrm{n}=42)$ & $11(26)$ & $3(7)$ \\
$42-48(\mathrm{n}=45)$ & $8(18)$ & $2(4)$ \\
$0-48(\mathrm{n}=578)$ & $238(41)$ & $66(11)$ \\
\hline
\end{tabular}

experience a delay in feeding (OR 2.2, 1.3 to 3.8 ), to have a lower birthweight (OR 2.09, 1.24 to 3.53 ), to have a smaller head size (OR $0.67,0.56$ to 0.81 ), to have haemoglobin concentrations $210 \mathrm{~g} / 1$ or above (OR 2.94, 1.35 to 6.39) and a higher TSH (OR 1.03, 1.01 to 1.05), and for their mothers also to have a TSH at $5 \mathrm{IU} / 1$ or above (OR 2.51, 1.37 to 4.62 ).

These risk factors were entered into a multiple logistic regression model, adjusting for variables which satisfied the following criteria: (i) an odds ratio different from unity at the 5\% significance level on univariate analysis; (ii) an odds ratio more than $20 \%$ away from unity on univariate analysis; (iii) a variable of hypothesised biological significance. On this basis, the following variables were entered: postnatal age at sampling, sex of infant, gestational age, time since last feed, birthweight, birth length, head size, rectal temperature, infant haemoglobin, $\mathrm{TSH}$ and free T4, maternal parity, $\mathrm{TSH}$, and ambient temperature.

Table 3 shows the risk factors which remained significantly associated with moderate hypoglycaemia: postmaturity (OR 2.62, $95 \%$ CI 1.00 to 6.86 ), low birthweight (OR $2.11,1.02$ to 4.36 ), head circumference (OR $0.59,0.43$ to 0.81$)$, infant haemoglobin $210 \mathrm{~g} / 1$ or above (OR 2.77, 1.15 to 6.67), maternal TSH 5 IU/1 or above (OR 3.08, 1.55 to 6.13 ) and higher infant TSH (OR 1.02, 1.00 to 1.04).

A delay in feeding, associated with hypoglycaemia on univariate analysis, did not remain as a significant variable after multivariate analysis. However, the effect of feeding delay was modified by age of the infant (likelihood ratio test for interaction $\mathrm{p}=0.08$ ) and therefore the stratified odds ratios are reported: age $0-11$ hours (OR 1.34, 0.56 to $3.26, \mathrm{p}=0.51$ ); age $12-23$ hours (OR 4.09, 1.45 to 11.53 , p = 0.004 ); age $24-35$ hours (OR 2.27, 0.43 to 12.07, $\mathrm{p}=0.32$ ); age 36-47 hours (no cases).

Population attributable risk fractions were calculated for significant clinical risk factors (table 3). The most important risk fractions for moderate hypoglycaemia were delay in feeding, low birth weight and high maternal TSH.

To examine the relation between proportionality of the size of the neonate and the risk of neonatal hypoglycaemia, we entered two measures of proportionality, ponderal index (PI = the weight of the infant in $\mathrm{g} \times 100$, divided by the birth length in $\mathrm{cm}^{3}$ ) and head circumference to birth weight ratio (hwr $=$ the head circumference in $\mathrm{cm}$ divided by the birthweight in $\mathrm{kg}$ ) into the logistic regression in place of birthweight and birth length (for PI) and birthweight and head circumference (for hwr), respectively. The results showed disproportionately growth retarded neonates to have a greater risk of moderate hypoglycaemia: the risk of moderate hypoglycaemia fell as the PI increased (OR $0.29,95 \%$ CI 0.10 to $0.87, \mathrm{p}=$ 0.028 ) and increased as the head circumference to birthweight ratio increased (OR 1.41, CI 1.12 to 1.79 ), the odds reflecting the change in risk for a unit change in PI or hwr. Mean (SD) PI and hwr values were 2.55 (0.29) and 12.34 (1.56), respectively. This suggests that the risk of hypoglycaemia is associated with growth retardation in the third trimester, with thinner infants, and thin infants with larger heads being more at risk. The overall finding of an association between moderate hypoglycaemia and a small head circumference is therefore reversed among infants with lower birthweights.

Using stepwise linear regression, with blood glucose as the dependent variable, we studied associations with the following independent variables: for mothers, age, height, weight, haemoglobin, $\mathrm{TSH}$, free $\mathrm{T} 4$, antenatal visits, admission ward, parity, ethnic group; for 
Table 3 Risk factors (odds ratios and 95\% confidence intervals) for moderate hypoglycaemia (less than $2.0 \mathrm{mmol} / \mathrm{l}$ ) adjusted for confounders by multiple logistic regression

\begin{tabular}{|c|c|c|}
\hline Exposure & $\begin{array}{l}\text { Risk factors for moderate } \\
\text { hypoglycaemia } \\
\text { (odds ratios and } 95 \% \text { CI) }\end{array}$ & $\begin{array}{l}\text { Adjusted } \\
\text { attributable risk } \\
\text { fraction }\end{array}$ \\
\hline \multicolumn{3}{|l|}{ Interval since last feed (hrs) } \\
\hline$>3 \mathrm{hrs} v s<3$ & $1.47(0.69-3.13)$ & 0.43 \\
\hline $0-11.9$ & $1.34(0.56-3.26)$ & \\
\hline $12-23.9$ & $4.09(1.45-11.53)$ & \\
\hline $24-35.9$ & $2.27(0.43-12.07)$ & \\
\hline $36-48$ & - & \\
\hline \multicolumn{3}{|l|}{ Gestation } \\
\hline post term vs term & $2.62(1.00-6.86)$ & 0.075 \\
\hline \multicolumn{3}{|l|}{ Parity } \\
\hline multiparate $v s$ primiparate & $1.25(0.67-2.34)$ & \\
\hline \multicolumn{3}{|l|}{ Birthweight } \\
\hline$<2.5 \mathrm{~kg} v s>2.5 \mathrm{~kg}$ & $2.11(1.02-4.36)$ & 0.247 \\
\hline Birth length $(\mathrm{cm})$ & $1.17(0.95-1.43)$ & \\
\hline Head size $(\mathrm{cm})$ & $0.59(0.43-0.81)$ & \\
\hline \multicolumn{3}{|l|}{ Rectal temperature } \\
\hline$<36^{\circ} \mathrm{C}$ vs $>36^{\circ} \mathrm{C}$ & $0.77(0.37-1.62)$ & \\
\hline \multicolumn{3}{|l|}{ Infant haemoglobin } \\
\hline$>21 \mathrm{~g} / \mathrm{dl} v s<21 \mathrm{~g} / \mathrm{dl}$ & $2.77(1.15-6.67)$ & 0.097 \\
\hline Infant TSH (mU/l) & $1.02(1.00-1.04)$ & \\
\hline Infant free $\mathrm{T} 4(\mathrm{pmol} / \mathrm{l})$ & $0.99(0.95-1.02)$ & \\
\hline \multicolumn{3}{|l|}{ Maternal TSH } \\
\hline$>5 \mathrm{IU} / 1$ vs < $5 \mathrm{IU} / 1$ & $3.08(1.55-6.13)$ & 0.184 \\
\hline \multicolumn{3}{|l|}{ Ambient temperature } \\
\hline$<25^{\circ} \mathrm{C} v s>25^{\circ} \mathrm{C}$ & $1.28(0.64-2.58)$ & \\
\hline $\begin{array}{l}\text { Sex } \\
\quad \text { Female vs male }\end{array}$ & $1.22(0.69-2.17)$ & \\
\hline
\end{tabular}

Odds ratios represent the risk of moderate hypoglycaemia in the presence of the categorical variable or with a unit increase in the continuous variable. Those results shown in bold achieve variable or with a unit increase in the

Table 4 Independent predictors of blood glucose in term infants in multiple linear regression analysis $(n=515)$

\begin{tabular}{lll}
\hline Variable & $\begin{array}{l}\text { Estimated effect on blood } \\
\text { glucose in mmol/l }(95 \% \mathrm{CI})\end{array}$ & $p$ Value \\
\hline Age (hours) when bled after birth & $0.012(0.006$ to 0.018$)$ & $<0.001$ \\
Infant haemoglobin $(\mathrm{g} / \mathrm{dl})$ & $-0.06(-0.09$ to -0.03$)$ & $<0.001$ \\
Maternal haemoglobin $(\mathrm{g} / \mathrm{dl})$ & $0.04(0$ to 0.07$)$ & 0.05 \\
\hline
\end{tabular}

The estimated effect on blood glucose is the change in blood glucose ( $\mathrm{mmol} / \mathrm{l})$ for a unit increase in a continuous variable.

Table 5 Summary of risk factors from multiple regression

\begin{tabular}{ll}
\hline Outcome definition & $\begin{array}{l}\text { Significant independent risk } \\
\text { factors } \text { or associations }\end{array}$ \\
\hline Moderate hypoglycaemia (less than $2.0 \mathrm{mmol} / \mathrm{l})$ & $\begin{array}{l}\text { High infant haemoglobin } \\
\text { Postmaturity }\end{array}$ \\
& Low birthweight $<2.5 \mathrm{~kg}$ \\
Small head size \\
High infant TSH \\
Pigh maternal TSH \\
Infant haemoglobin (negative) \\
Maternal haemoglobin (positive)
\end{tabular}

infants, sex, gestational age, weight, length, head circumference, rectal temperature, haemoglobin, $\mathrm{TSH}$, free $\mathrm{T} 4$, interval since last feed, and ambient temperature (table 4). After adjusting for all other variables, only infant haemoglobin and maternal haemoglobin were negatively and positively correlated, respectively, with infant blood glucose.

Table 5 summarises the significant associations with blood glucose and hypoglycaemia after multiple regression.

\section{Discussion}

We deliberately sampled our population during three phlebotomy sessions each day. While not a random process, selection bias is unlikely as the infant's blood glucose concentration was not ascertainable from the labour ward register. The sample was therefore representative of apparently well, newborn infants delivered in a hospital where most mothers were poor and nutritionally compromised.

For logistical reasons, cotside screening for hypoglycaemia in this setting is only performed in the special care baby unit, not the postnatal wards, so we were not sampling a privileged population in which risk factors had been taken into account. Some caution is needed in interpreting the clinical assessment of gestational age. We used the Capurro method (a simpler modification of the Dubowitz assessment) and avoided issues of interobserver reliability by having all assessments performed by one observer, an experienced neonatal clinician (author SR), but the method has not been formally validated for Nepalese infants.

The prevalence of hypoglycaemia (41\% mild, $11 \%$ moderate) was much higher than studies from industrialised countries have indicated but similar to our previous study which reported prevalence data from corrected glucose strip values rather than laboratory glucose measurements. For mild hypoglycaemia prevalence rates in the first two days, Holtrop ${ }^{13}$ reported $8-15 \%$ and Hawdon $20-23 \%$ (Hawdon J, personal communication); for moderate hypoglycaemia Heck and Erenberg, ${ }^{14}$ using heelprick specimens which tend to overestimate hypoglycaemia, found a 5\% prevalence. Our figures would probably have been higher if special care baby unit admissions had been included, or if we had studied a rural population in which health and nutrition might be poorer still.

The full linear regression model explained only $8 \%$ of the variance for infant blood glucose. We found a strong positive association between glucose and maternal haemoglobin and a negative association with infant haemoglobin. Maternal anaemia is probably a proxy for maternal malnutrition during late pregnancy, but might also influence the transplacental acquisition of fetal metabolic reserves in the last trimester.

The independent association between a high infant haemoglobin and hypoglycaemia could have several explanations. Postmaturity and growth retardation were adjusted for in the analysis, suggesting a direct association between high infant haemoglobin and low blood glucose, rather than through a confounder. One explanation is methodological: red cell glucose is lower than plasma glucose, so samples with a higher red cell mass may give lower glucose readings when a whole blood assay is used. We found no association between haemoglobin and glucose in maternal samples, but the range of maternal haematocrit is well below neonatal values, and the interaction between high haematocrit and discrepant blood glucose concentrations is stronger when the packed cell volume exceeds $60 \%$. Red blood cells are also glucose consumers so a high red cell mass will increase glucose consumption. Our specimens, however, were collected directly into perchloracetic acid and this process would not have occurred after phlebotomy.

Perhaps poor maternal nutritional status and impaired placental function are linked through 
various mechanisms, leading to a higher infant haemoglobin and vulnerability to hypoglycaemia. Erythropoietin, which is raised in small for gestational age infants, ${ }^{15}$ could play a part in this mechanism. Overall, a high infant haemoglobin accounted for less than $10 \%$ of the attributable risk for moderate hypoglycaemia.

"Textbook" risk factors were common in this population: $32 \%$ of infants were low birthweight, $24 \%$ had not been fed in the previous three hours, $7 \%$ were polycythaemic with a haemoglobin of $210 \mathrm{~g} / 1$ or above, $8 \%$ were post-term, and in winter all were nursed in a suboptimal thermal environment, with $20 \%$ hypothermic. After adjusting for potential confounders, low birthweight, postmaturity, a smaller head size, and polycythaemia were confirmed as risk factors for moderate hypoglycaemia as well as maternal anaemia and a raised maternal TSH.

The finding that small head circumference is associated with hypoglycaemia seemed surprising given the importance of brain size for glucose metabolism. Clearly, associated gestational age and low birthweight effects may have been only partly controlled for in this study. We were therefore interested in the relation between proportionality of the size of the newborn infant and the risk of neonatal hypoglycaemia. Two measures of proportionality, ponderal index (PI) and head circumference to birthweight ratio (hwr), were evaluated. The results showed disproportionately growth retarded neonates to have a greater risk of moderate hypoglycaemia: the risk fell as the ponderal index increased - that is, infants were fatter-but increased as the head circumference to birthweight ratio increased. Hypoglycaemia seems to be associated with growth retardation in the last trimester, causing thinness, and is greater in low birthweight infants with larger heads. This observation seems to support the idea that glucose consumption increases with a higher brain: body mass ratio, ${ }^{16}$ but the data are insufficient to vindicate the hypothesis that glucose requirements correlate more closely with brain than body weight. ${ }^{17}$

The mechanism by which postmaturity predisposes to hypoglycaemia is not clear. Polycythaemia and wasting are two possible explanations, but both were adjusted for in the analysis. Some other mechanism associated with postmaturity, such as declining placental efficiency, might be responsible. From the population attributable risk, removal of postmaturity and low birthweight might prevent $25 \%$ and $8 \%$, respectively, of moderate hypoglycaemia, but neither is feasible in this setting.

There was an interaction effect between age and feeding delay on the risk of hypoglycaemia. Infants in the age group 12-24 hours had four times the risk of moderate hypoglycaemia if there was a delay in feeding. This observation coincides with the critical period between the exhaustion of glycogen reserves and the onset of gluconeogenesis and mobilisation of alternative fuels. The attributable risk fraction for the effect of feeding delay on hypoglycaemia was high $(43 \%)$ and emphasises the need to promote early breastfeeding.

Surprisingly, hypothermia was not identified as a significant risk factor for moderate hypoglycaemia. It seems that the clinical association between hypothermia and hypoglycaemia, widely described in neonatal textbooks, may be heavily confounded by age: infants soon after birth are much more likely to be both hypothermic and hypoglycaemic. Our findings do not, however, justify clinicians paying less attention to hypothermia. In the next paper we show that there is a significant relation between hypothermia and reduced ketone availability, after adjusting for age, so hypothermia may still present a significant risk to normal neonatal metabolic adaptation.

New risk factors identified in our study were a raised maternal TSH and maternal anaemia, which emerged in the linear regression of blood glucose. Iodine deficiency is common in Nepal, and laboratory studies in sheep show that impaired maternal thyroid status predisposes the newborn to hypoglycaemia. ${ }^{18}$ An intriguing hypothesis is that maternal hypothyroidism impairs neurodevelopment partly through an indirect effect on glucose metabolism in the neonatal period. The weak association between hypoglycaemia and high infant TSH is probably clinically insignificant because concentrations fall rapidly after birth, and may possibly be influenced by stress in labour.

Maternal anaemia is associated with several other risk factors, such as low birthweight and infant polycythaemia, but might also affect placental function adversely in a way which increases infant vulnerability to hypoglycaemia.

We have shown that hypoglycaemia is surprisingly common among apparently healthy neonates in a developing country setting. We were unable to explain much of the variance in blood glucose concentrations in the newborn period. Important corollary questions that arise from such a high prevalence are whether alternative fuels mitigate the effects of hypoglycaemia, and what are the long term consequences for infant development? Simple low cost measures such as antenatal care, to reduce maternal anaemia, and early feeding especially for low birthweight infants, or those disproportionally growth retarded, could have a significant impact on the prevalence of hypoglycaemia. Independent risk factors such as low birthweight (and disproportionate growth retardation), postmaturity, and polycythaemia together account for as much attributable risk as feeding delay, but will be more difficult to influence in the short term. New associations with maternal thyroid status and anaemia should stimulate interest for research into the interrelations of maternal nutrition, placental function, and metabolic adaptation in the newborn period.

This study was funded by a grant from the British Department for International Development. Deb Pal was a Wellcome Trust Research Training Fellow.

We thank Professor Glyn Lewis for his advice. 
Ashworth A, Waterlow JC. Infant mortality in developing countries. Arch Dis Child 1982;57:882-4.

2 Lucas A, Morley R, Cole TJ. Adverse neurodevelopmental outcome of moderate neonatal hypoglycaemia. BMF 1988;297:1304-8.

3 Koh TH, Aynsley-Green A, Tarbit M, Eyre JA. Neural dysfunction during hypoglycaemia. Arch Dis Child 1988;63:1353-8.

4 Koh TH, Eyre JA, Aynsley-Green A. Neonatal hypoglycaemia - the controversy regarding definition. Arch Dis Child 1988;63:1386-8.

5 Cornblath J, Reisner SH. Blood glucose in the neonate and its clinical significance. $N$ Engl F Med 1965;273:378-80.

6 Fluge G. Clinical aspects of neonatal hypoglycaemia. Acto Paediatr Scand 1974;63:826-32.

7 Anderson S, Shakya KN, Shrestha LN, Costello AM. Hypoglycaemia: a common problem among uncomplicated newborn infants in Nepal. 7 Trop Pediatr cated newborn

8 Hawdon JM, Ward-Platt MP, Aynsley-Green A. Neonatal hypoglycaemia-blood glucose monitoring and baby feeding. Midwifery 1993;9:3-6.

World bank. From Plan to Market. World Development Report. 1996. New York: The World Bank, 1996.

10 Ellis M, Manandhar N, Shakya U, Manandhar DS, Fawdry A, Costello AM de L. Postnatal hypothermia and cold stress among newborn infants in Nepal monitored by continuous ambulatory recording. Arch Dis Child Feta Neonatal Ed 1996;75:F42-5.
11 Capurro H, Konichezky S, Fonseca D, Caldeyro-Garcia T. A simplified method for diagnosis of gestational age in the newborn infant. $\mathcal{F}$ Pediatr 1978; 93:120-2.

12 Bruzzi P, Green SB, Byar DP, Brinton LA, Schairer C. Estimating the population attributable risk for multiple risk factors using case-control data. Am $\mathcal{f}$ Epidemiol 1985;122:904-14

13 Holtrop PC. The frequency of hypoglycaemia in full-term large and small for gestational age newborns. Am f Perinatol 1993:10:150-4.

14 Heck LJ, Erenberg A. Serum glucose levels in term neonates during the first 48 hours of life. F Pediatr 1987;110:11922

15 Lemery DJ, Santolaya J, Serre AF, et al. Serum erythropoietin in small-for-gestational age fetuses. Biol Neonate 1994; 65:89-93.

16 Kalhan SC, Oliven A, King KC, Lucero C. Role of glucose in the regulation of endogenous glucose production in the human newborn. Pediatr Res 1986; 20:49-52.

17 Bier DM, Leake RD, Haymond MW, et al. Measurement of the "true" glucose production rate in infancy and childhood with 6,6-dideuteroglucose. Diabetes 1977;26:1016-23.

18 Silver M, Fowden AL, Knox J, Ousey JC, Franco R, Rossdale PD. Sympathoadrenal and other responses to hypoglycaemia in the young foal. I Reprod Fertil Suppl 1987;35:607-14 